\title{
Combined Effect of Three Pesticides (Zoom, Topik and Ortiva) and Phosphorus Fertilization on Some Physicochemical Parameters of Soil
}

\author{
A. Ketif $^{1}$, R. Djamaï ${ }^{1}$ C. Abdennour ${ }^{1} \&$ S. Seridi ${ }^{2}$ \\ ${ }^{1}$ Department of Biology, Faculty of Sciences, University of Badji Mokhtar-Annaba, Annaba, Algeria \\ ${ }^{2}$ Technical Institute for Field Crops, Guelma, Algeria \\ Correspondence: A. Ketif, University of Badji Mokhtar-Annaba, Faculty of Sciences, Department of Biology BP \\ 12, Annaba 23000, Algeria. E-mail: amel.magister75@hotmail.fr
}

Received: June 30, 2014 Accepted: September 10, 2014 Online Published: December 15, 2014

doi:10.5539/jas.v7n1p30 URL: http://dx.doi.org/10.5539/jas.v7n1p30

\begin{abstract}
The purpose of this study was to verify the effect of three pesticides (Zoom, Topik and Ortiva) on some physicochemical parameters of soil. To do this, phosphate fertilizer was applied before planting and pesticides were sprayed pre- and post- emergence of Durum wheat. Particle size analysis showed that the soil was characterized by a clay texture and the value of residual humidity does not exceed $8 \%$. The study of $\mathrm{pH}$ showed a remarkable seasonal variability; it was in the vicinity of neutrality at the beginning of culture (7.22) to the vicinity of acidity after crop harvest (5.78), thus the change in $\mathrm{pH}$ water was due to the phenomenon of dilution. The electrical conductivity proved that the soil was not saline. The content of soil organic matter was experiencing significant seasonal variation. After applying different doses of phosphate fertilizers, soil phosphorus varied remarkably with the seasons, which can be affected by adsorption, precipitation, heading stage, and the presence of clay cation $\mathrm{Fe}, \mathrm{Al}$ and $\mathrm{Ca}$. It was also noticed an increase in the content of soil available phosphorus during the tillering stage, which is due to the phenomenon of desorption and dissolution. The existence of traces of pesticides indicates that the Topik molecules are more resistant to degradation.
\end{abstract}

Keywords: phosphate fertilizer, pesticides, Zoom, Topik, Ortiva, Durum wheat

\section{Introduction}

Phosphorus after nitrogen is the most important for the growth and development of field crops. Applied in excess, it accumulates in the top soil and can contribute to the eutrophication of surface waters. However, soil poor in phosphorus affect agriculture production negatively (UK Agriculture, 2010). It is therefore important to find a balance between the supply and demand for soil P, especially in intensive cropping systems. During recent years, the interest of the public but also researchers with respect to pesticide usages and its impact on the environment has been increasing (Albin, 1999). It is known that the physical environment is made of air, soil and water; there by the permanent exchanges between these compartments, pesticide introduced in one of them can contaminate the others (Feuillet et al., 2007). Research on the dispersion of pesticides in the environment has started after finding that these products have contaminated vast areas of the biosphere. Indeed, pesticides can be quite environmentally harmful, through their effects on wildlife and wild flora, biodiversity and water supply systems and contaminate runoff (Zhang et al., 2007). Countries generally use different methods to reduce the use of these products in agriculture by regulating the methods used to limit their application (Edwards et al., 2005). However, only few countries actually impose taxes on pesticides in order to limit their application (Rosinger \& Kocher, 2007).

\section{Materials and Methods}

This work was carried out in the Technical Institute for field crops at Guelma province. The objectives of the institute are to supply certified pesticides after testing them in the field. It investigates the entire technical process related to soil physical and chemical environment in order to improve crop productions and preserve the environment.

\subsection{Pesticide Molecules}

The pesticides used in this station are widely used for cereal cultures. Topik is a selective herbicide, comprising two active ingredients; clodinafop-propargyl $(80 \mathrm{~g})$ and cloquintocet-mexyl $(20 \mathrm{~g})$. Zoom is also a selective 
herbicide contains two actives materials; dicamba (65\%) and triasulfuron (4.1\%). Ortiva is a fungicide used to inhibit fungi respiration.

\subsection{Phosphate Fertilizer}

Different doses of phosphate fertilizer were prepared in the field by applying triple concentrated superphosphate at $45 \%$ :

- 0 unit phosphorus dose $\mathrm{T} 0$ on subplots 01-13-20

-92 Units of phosphorus for Tr dose subplots 02-10-21

-30 Units of phosphorus dose T1 subplots 03-14-19

-45 Units of phosphorus dose T2 subplots 04-09-18

-60 Units of phosphorus dose T3 subplots 05-08-17

-25 Units of phosphorus dose T4 on subplots 06-11-16

-22 Units of phosphorus dose T5 on subplots 07-12-15.

\subsection{Field Test}

The experiment is conducted in 7 randomized blocks, each one consists of three sub-plots, and the sub-plots were distributed in the field with randomly drawing fate. The length of each sub-plot is $10 \mathrm{~m}$, while the width is $1 \mathrm{~m}$. phosphorus spreading were applied before planting on October 15, 2010, followed by sowing on November 10, 2010, while the spraying of pesticides was carried out after the first rain (January 15, 2011).

\subsection{Sampling}

Sampling was carried out in two periods; the first period was on February 4, 2011 and the second one was on April 2, 2011.

\subsection{Physicochemical Study of the Soil}

The physicochemical analysis of the soil was conducted by measuring water $\mathrm{pH}$ with a $\mathrm{pH}$ meter, the electrical conductivity by a conductivity meter, organic carbon by the Anne method, Apparent density by the method of the paraffin, the actual density by the pycnometer method, the porosity by the following formula $(\mathrm{Dr}-\mathrm{Da} / \mathrm{Dr}) \times 100$, particle size by the international method using the Robinson pipette, and Phosphorus concentration by the Joret-Hebert method.

\subsection{Determination of Residues}

The determination of pesticide residues was carried out by the HPLC method (sharing method) at FERTIAL laboratory, Annaba.

\subsection{Statistical Processing of Data}

Results were analyzed by statistical software 13.31 and MINITAB 14.1 .

\section{Results}

\subsection{Physicochemical Study of Soil}

\subsubsection{Grain Size}

Particle size analysis is used to find the distribution of less than $2 \mathrm{~mm}$ in class sizes of mineral particles (Baize, 2000). In our study on the particle size of the ground (Figure 1), we found that the percentage of clay is between $44.66 \%$ (block 1) and $57.66 \%$ (block 4), with an average of 50.90\%. The average of coarse soil of various blocks, including were $50.99 \%$ clay, $41.24 \%$ sand and $7.04 \%$ silt, and according to the triangle texture of Jammgne (Baize, 2000), the texture of our soil is dominated by clay. 


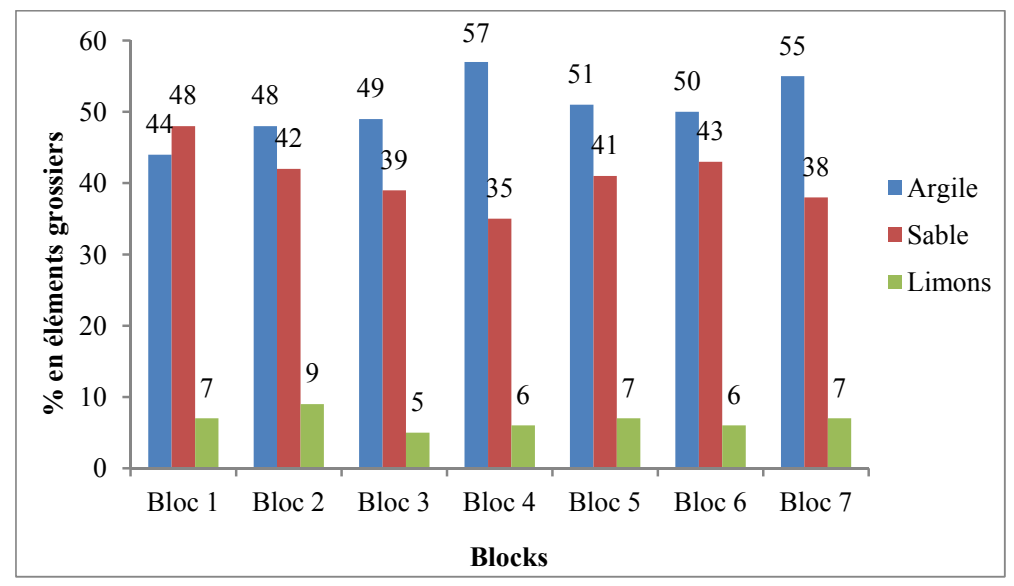

Figure 1. Levels of the soil grain sizes from different blocks

\subsubsection{Residual Soil Moisture}

During the crop cycle of Durum wheat, residual moisture is seasonally variable, with an overall average of $6.7 \%$ \pm 1.82 . Statistical analysis of variance shows that there was no significant difference between the means of the residual moisture of the various periods of the cultivation cycle of Durum wheat $(\mathrm{p}=0.394)$.

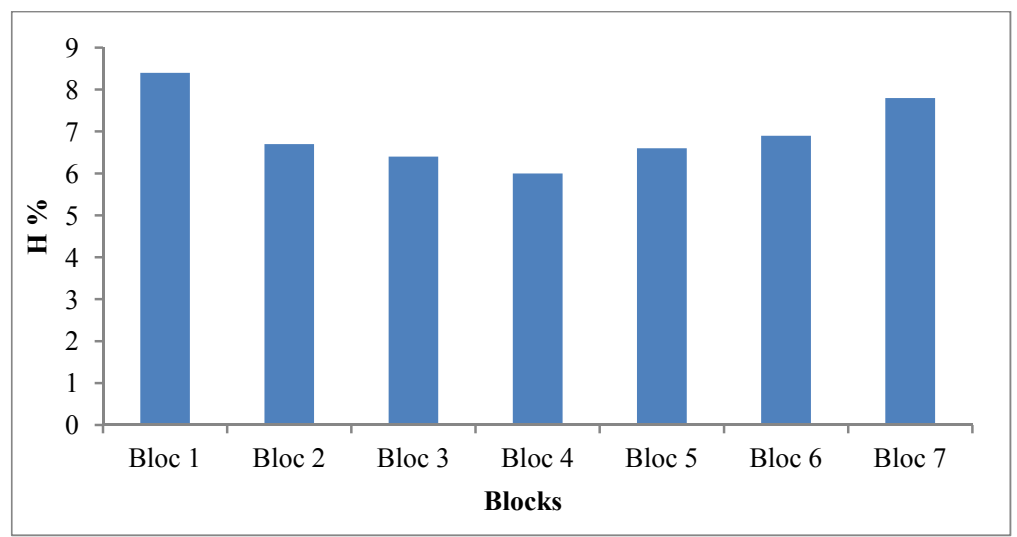

Figure 2. Soil residual moisture ratio during tillering stage of Durum wheat culture

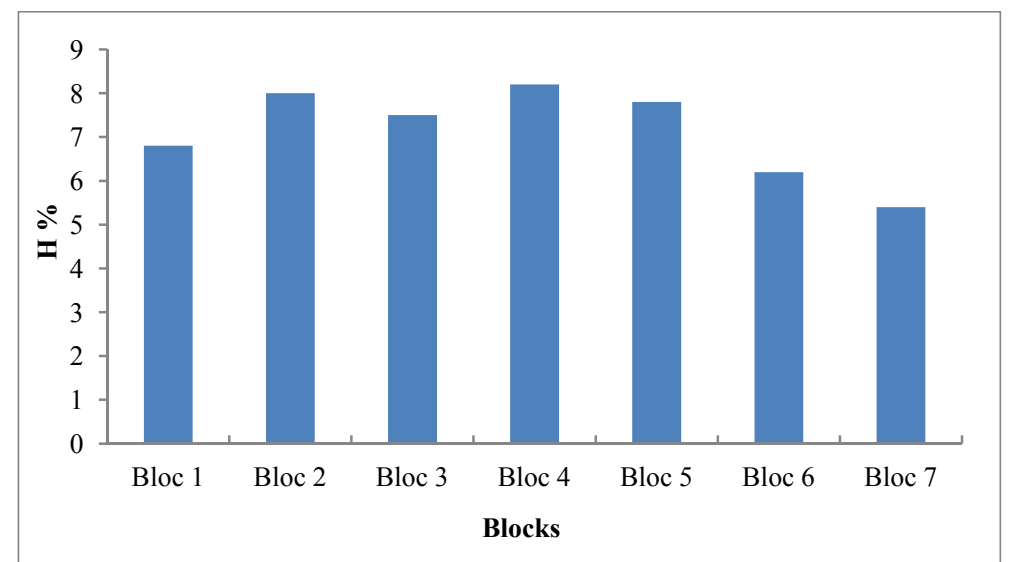

Figure 3. Residual moisture of the soil during the heading stage of Durum wheat culture 


\subsubsection{Soil $\mathrm{pH}$}

1) Water $\mathrm{pH}$

The $\mathrm{pH}$ is a model of expression of the concentration of $\mathrm{H}^{+}$ion in a liquid. Agronomically, the optimum $\mathrm{pH}$ can be set between 6.5 and 7.5 (Baize, 2000). During the culture cycle of Durum wheat, the study of soil water pH shows that the highest mean value recorded during the heading stage (7.86). Analysis of variance shows that there is a very highly significant difference between the means of different cycle periods of culture $(p=0.000)$.

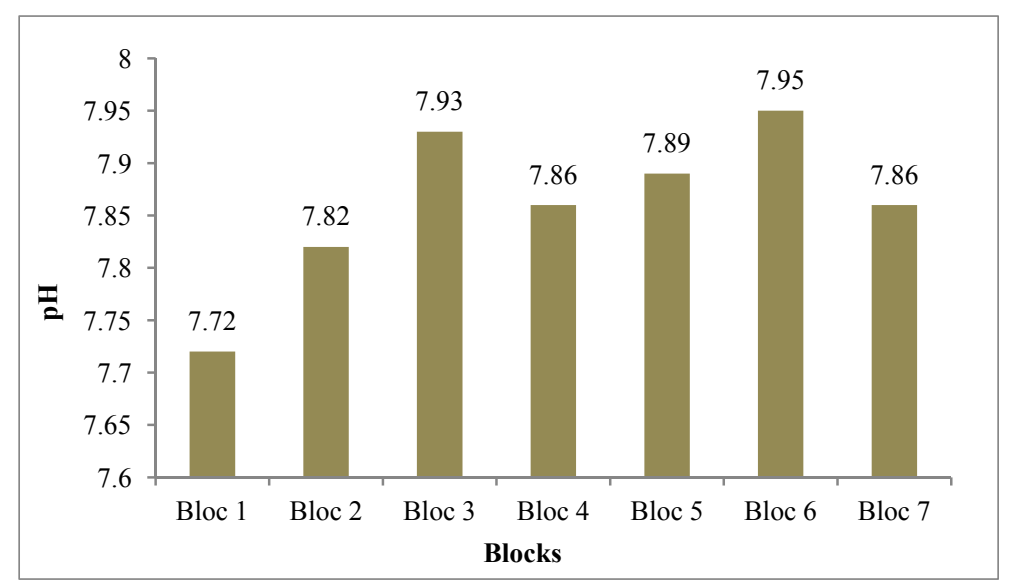

Figure 4. Water $\mathrm{pH}$ of soil water during tillering stage of Durum wheat culture

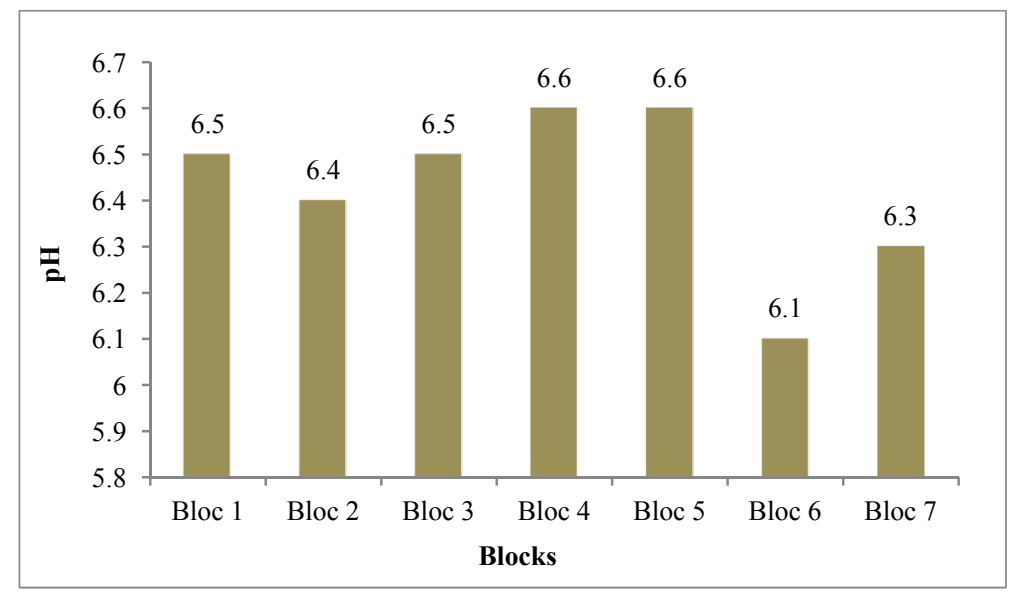

Figure 5. Water soil $\mathrm{pH}$ during the heading stage of Durum wheat culture

\section{2) The $\mathrm{KCl} \mathrm{pH}$}

During all the culture cycle of Durum wheat (Figures 6 and 7), the maximum average value recorded during the tillering stage was 7.46 , the mean value equal to 6.83 cycles with a standard deviation of 0.83 . Statistical analysis of variance shows that there was a very highly significant difference between the averages of different periods of the culture cycle of Durum wheat $(\mathrm{p}=0.000)$. 


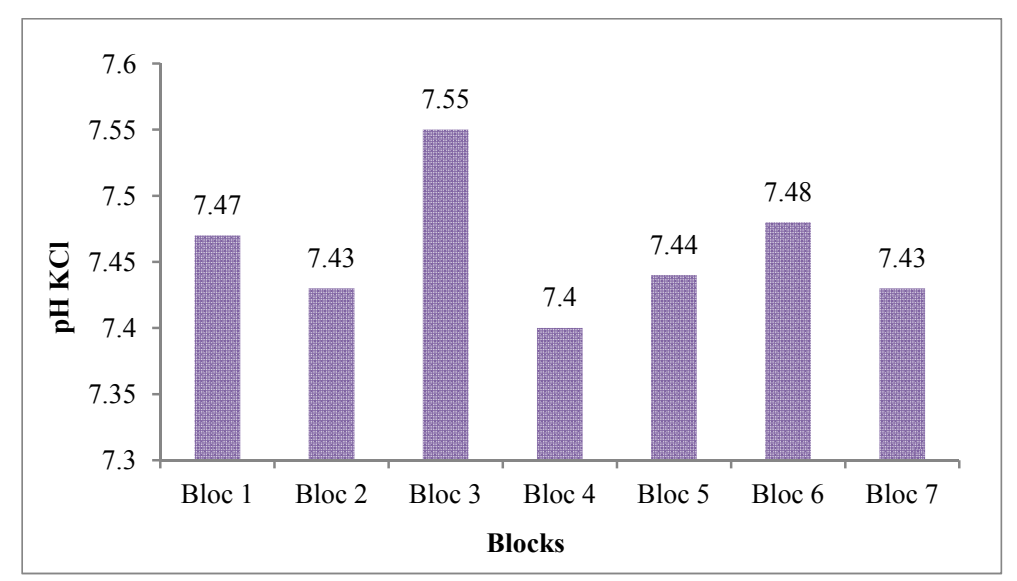

Figure 6. KCL pH in the soil during tillering stage of Durum wheat culture

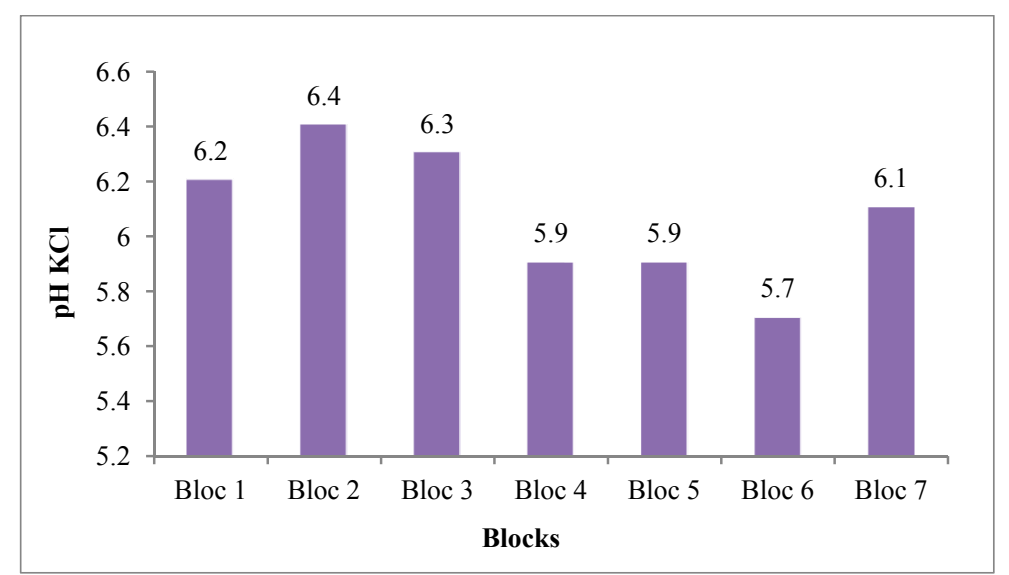

Figure 7. KCL pH in soil culture during the heading stage of Durum wheat culture

\subsubsection{The Electrical Soil Conductivity}

The study of the electrical conductivity during the culture cycle (Figures 8 and 9) gives us remark that the minimum average value is observed during the tillering stage $(0.08 \mathrm{~ms} / \mathrm{cm}$. Analysis of variance indicates there was a very highly significant difference between the means of the electrical conductivity of different periods of durum wheat cultivation $(\mathrm{p}=0.000)$.

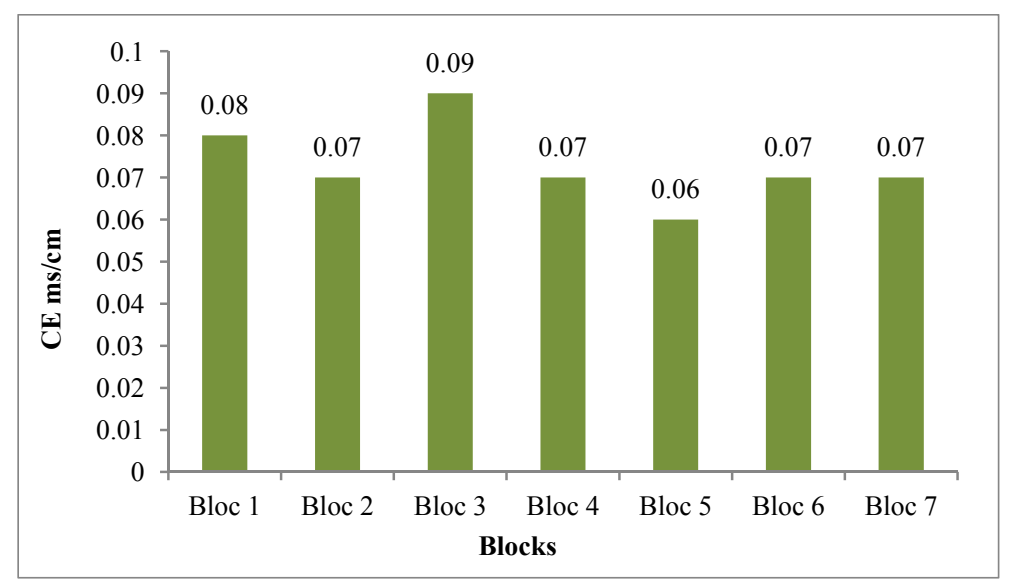

Figure 8 . The electrical conductivity of the soil during the tillering stage of the crop Durum wheat 


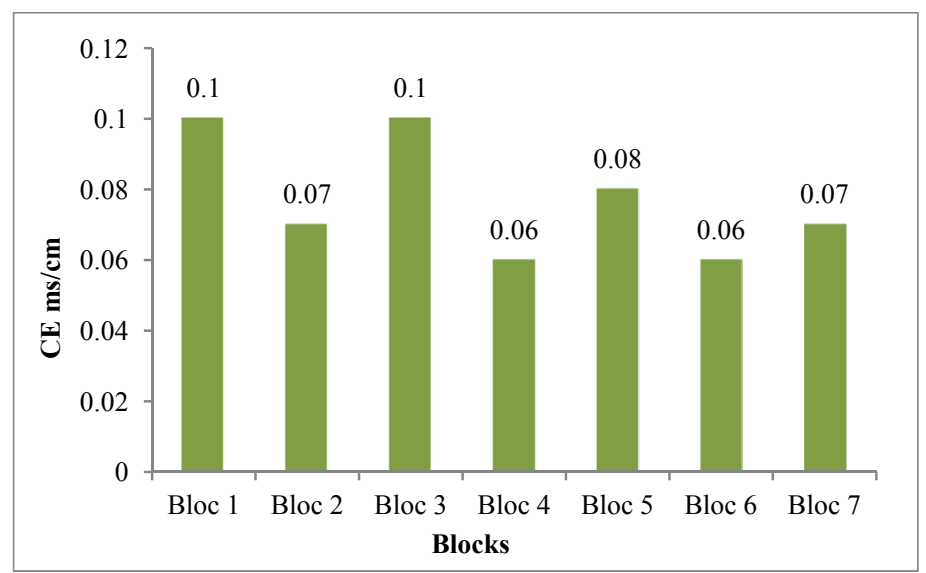

Figure 9. The electrical conductivity of the soil during the heading stage of the crop Durum wheat

\subsubsection{The Soil Organic Matter}

The study of the content of soil organic matter during the culture cycle of Durum wheat shows that the highest value recorded during the tillering stage $(6.96 \%)$, while the lowest value was observed for the heading stage with a mean of $1.08 \%$. The overall average for the entire cycle is $4.46 \%$ with a standard deviation of 2.39 . Analysis of variance shows that there is a highly significant difference between the means $(p=0.000)$.

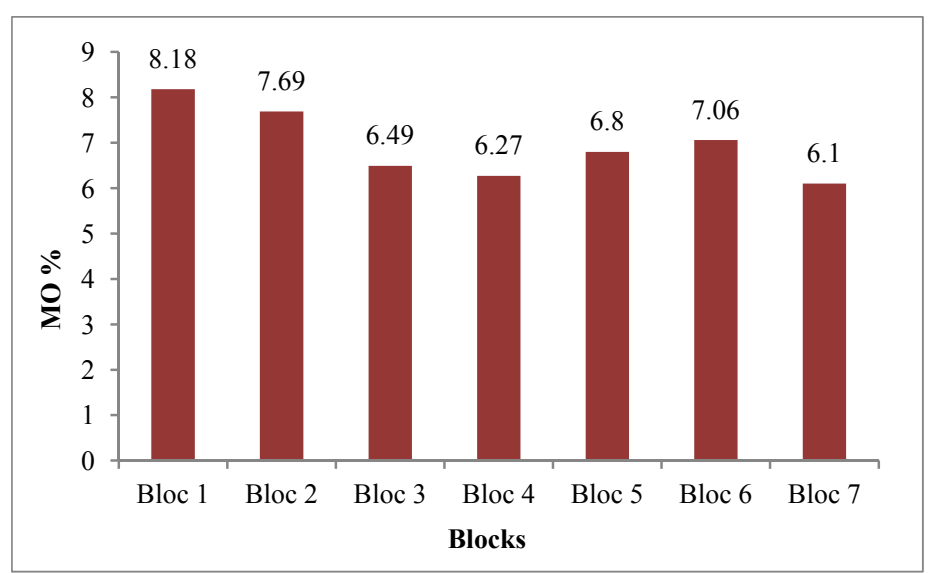

Figure 10. Percentage of soil organic matter during the tillering stage of Durum wheat

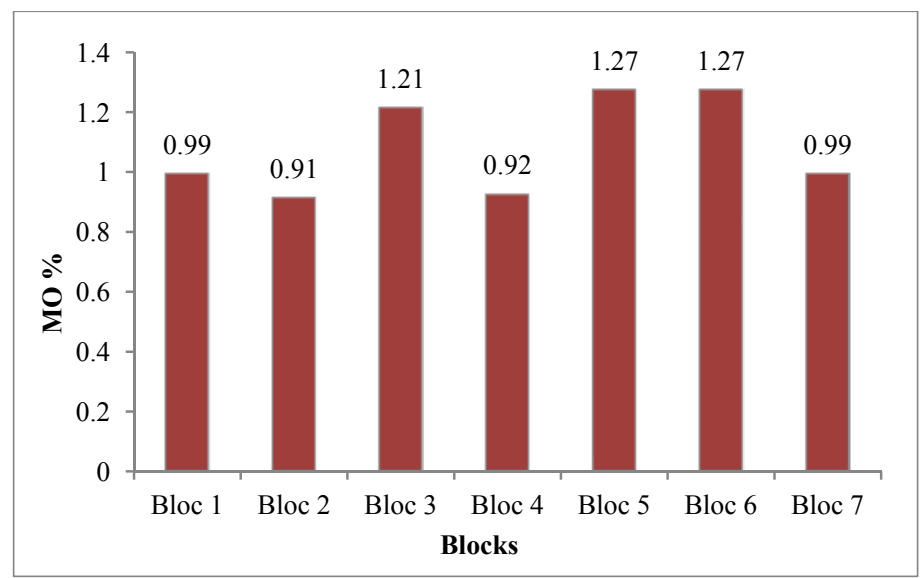

Figure 11. Rate of soil organic matter of the culture of Durum wheat during the heading stage 


\subsubsection{Assimilable Soil Phosphorus}

During the whole culture cycle (Figures 12 and 13), we see that the average value of all the blocks equal to 24.04 $\mathrm{mg} / \mathrm{kg}$, while the lowest value recorded during the tillering stage with a mean of $1.41 \mathrm{mg} / \mathrm{kg}$, the overall average for the entire cycle is $8.17 \mathrm{mg} / \mathrm{kg}$ and a standard deviation of 17.16 . The analysis of variance of different periods of the crop cycle, shows a very highly significant difference $(p=0.000)$.

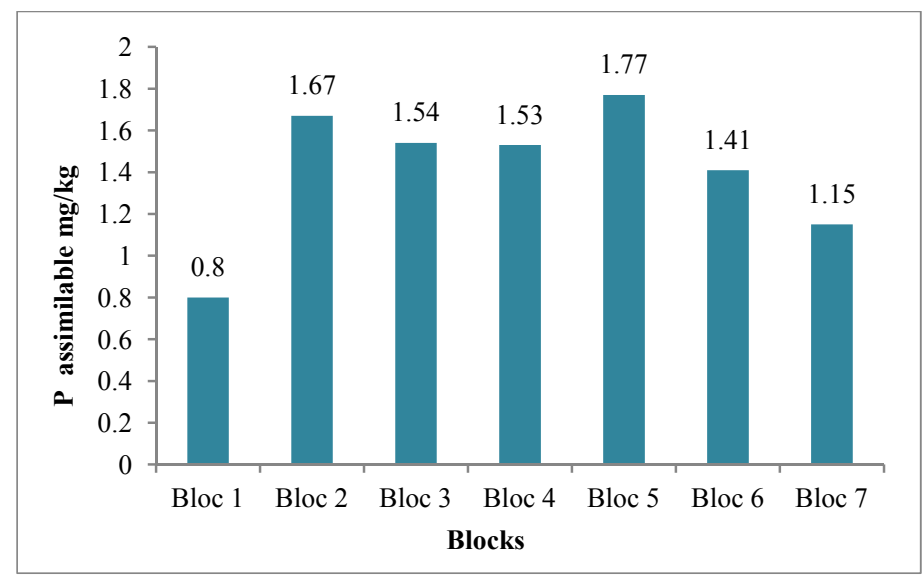

Figure 12. Assimilable phosphorus quantity of the soil during the tillering stage of Durum wheat

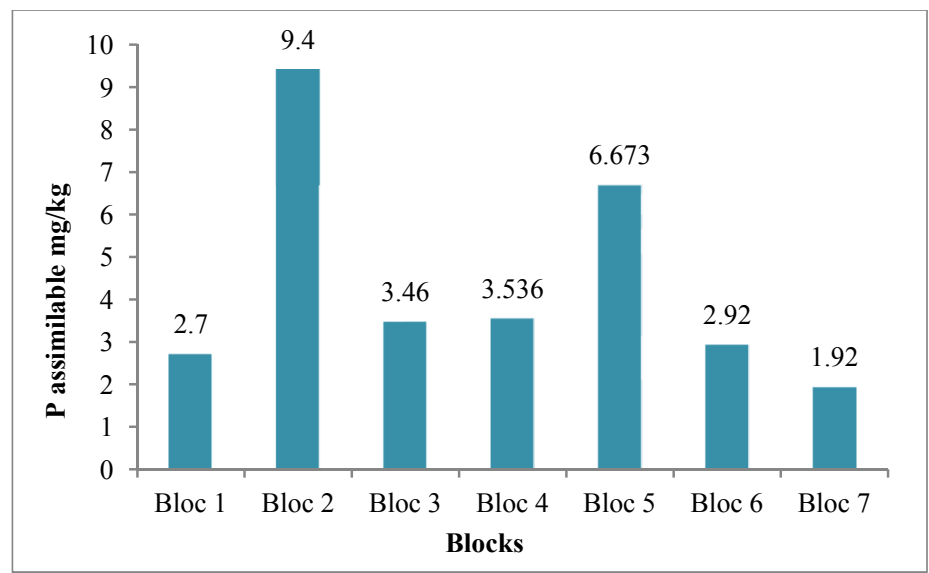

Figure 13. Assimilable phosphorus quantity of the soil during the heading stage of Durum wheat

\subsection{Determination of Pesticide Residues}

According to the HPLC, the following quantities of pesticides for the two periods were recorded. Research of Clodinofop-propagyl and Cloquintocet-mexyl in the soil sample gave results grouped in Table 1 and 2. The presence of certain quantities of soil residues confirms the presence of pollution.

Table 1. Result of pesticide dosing (mg/Kg DM) during the tillering stage

\begin{tabular}{llllllll}
\hline Block number & 1 & 2 & 3 & 4 & 5 & 6 & 7 \\
\hline First Levy & 279 & 421 & 371 & 354 & 452 & 292 & 265 \\
\hline
\end{tabular}

Table 2. Result of pesticide dosing ( $\mathrm{mg} / \mathrm{kg} \mathrm{DM})$ of inflorescence emergence stage

\begin{tabular}{llllllll}
\hline Block number & 1 & 2 & 3 & 4 & 5 & 6 & 7 \\
\hline Second Levy & 253 & 392 & 345 & 349 & 421 & 217 & 221 \\
\hline
\end{tabular}


From Figure 14 it was found that the soil contains traces of two active substances of the Topik; clodinofop-propagyl with and absorbance at $243.8 \mathrm{~nm}$ and the cloquintocet-mexyl with an absorbance at $280 \mathrm{~nm}$.

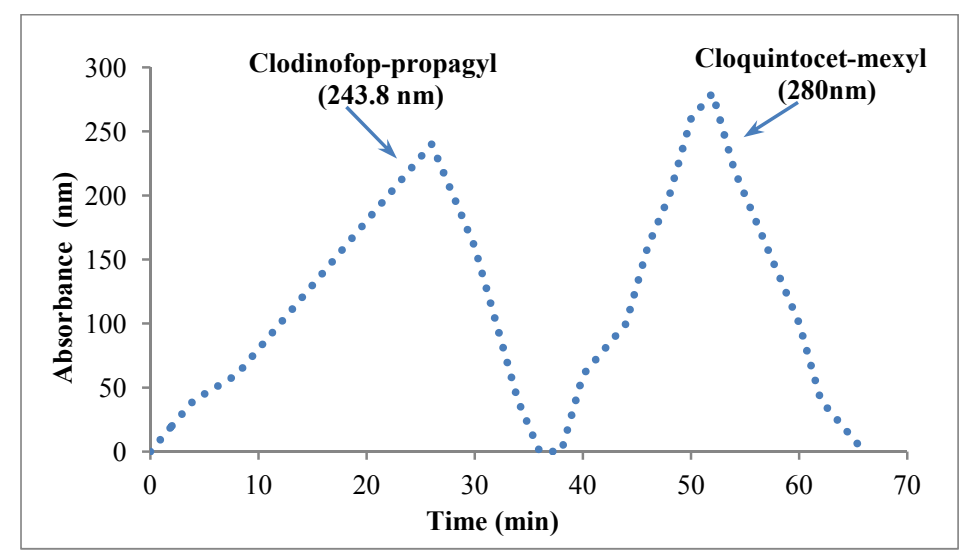

Figure 14. Absorbance spectrum of Clodinofop-propagyl and Cloquintocet-mexyl as a function of time

\subsection{Principal Component Analysis}

The principal component analysis of the tillering stage (Figure 15), showed that in the first explanatory component of $41.8 \%$ of the total variance, a positive correlations between available phosphorus, carbohydrates, proteins, and chlorophyll (a), (b) and $(\mathrm{a}+\mathrm{b})$ was observed. In the second component of explanatory of $17.7 \%$ of the total variance, there was a positive correlation between the rate of soil organic matter and chlorophyll (a) and $(\mathrm{a}+\mathrm{b})$ and a negative correlation with the soil available phosphorus. In the third component of the explanatory of $16.4 \%$ of the total variance, there were correlations between water $\mathrm{pH}$, electric conductivity and the soil $\mathrm{KCl} \mathrm{pH}$. Projection of the experiment in terms of principal component analysis (Figure 16) showed that the sub-plot fall into two separated groups, the first group includes subplots blocks 2, 4 and 5, which recorded the highest levels of available soil phosphorus, chlorophyll, soluble sugars, proteins and proline. However, the second group was formed by the subplot blocks 1, 3, 4, 6 and 7, these subplots characterized by average concentrations of available soil phosphorus, chlorophyll, soluble sugar, total protein and proline (under subplots blocks 3, 4 and 6) and the lowest levels were recorded in the subplot blocks 1 (control block) and block 7.

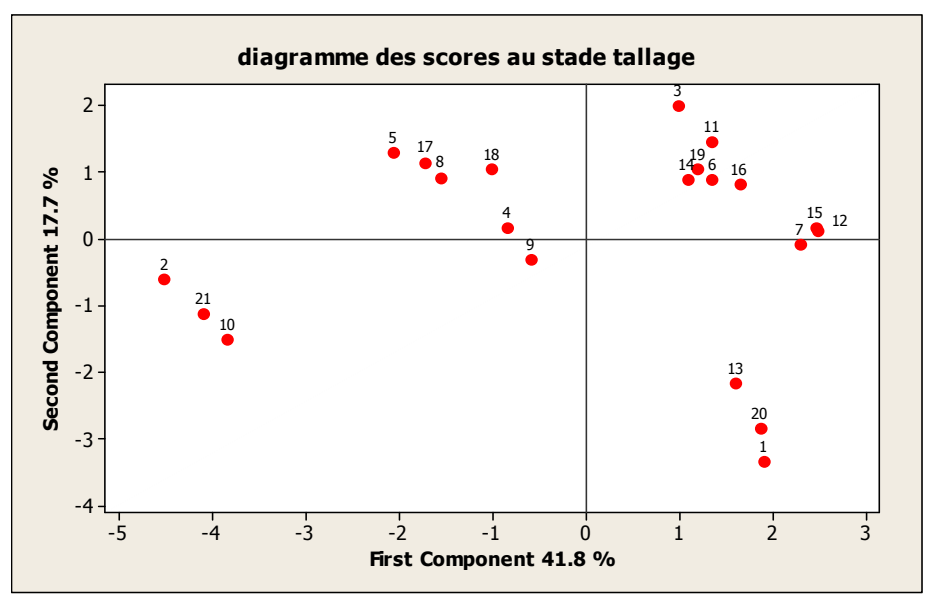

Figure 15. Principal component analysis of the projection of sub plots tillering 


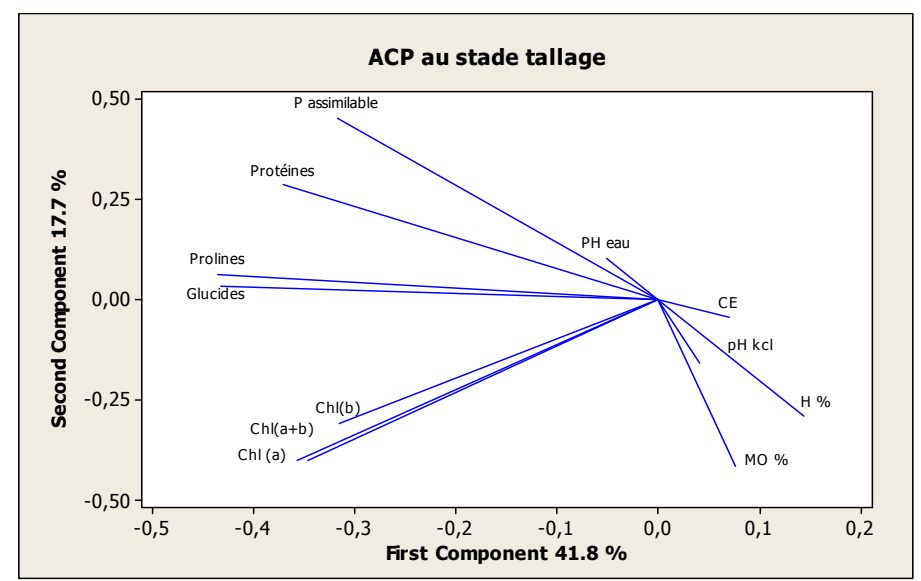

Figure 16. Principal Component analysis of the variables studied in the tillering stage

\subsection{Principal Component Analysis at the Inflorescence Emergence Stage}

The analysis of the main components(Figure 17) is indicated on the first explanatory component of $60.8 \%$ of the total variance, there was a positive correlation between wheat biochemical variables (total protein, soluble sugars, proline, chlorophyll (a), (b) and (a+b) and the concentration of soil assimilable phosphorus. However, in the second component of explanatory of $18.4 \%$ of the total variance, there was a positive correlation between water $\mathrm{pH}, \mathrm{KCl} \mathrm{pH}$ and electric conductivity of the soil and the concentration of soil assimilable phosphorus. Projection of different blocks (Figure 18) of the principal component analysis showed that the sub-plots of blocks 2 and 5 form a group characterized by higher levels soil assimilable phosphorus, chlorophyll, soluble sugars, total protein and proline, while subplots of blocks 1 (control), 7, 3 and 4 were characterized by average concentrations (subplots blocks 3, 4 and 6) and low concentration of sub-plot blocks 1 (control) and 7.

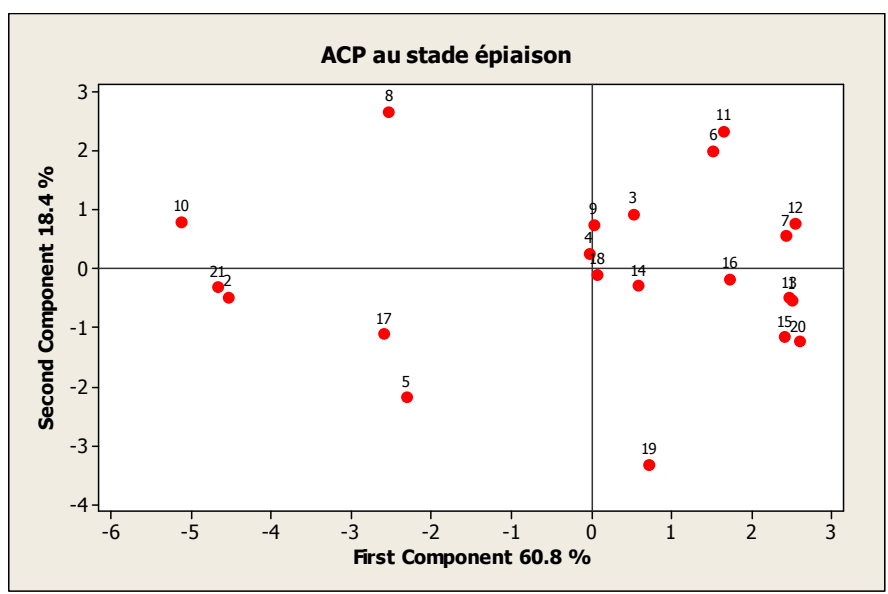

Figure 17. Principal component analysis of the projection of sub-plots inflorescence emergence step 


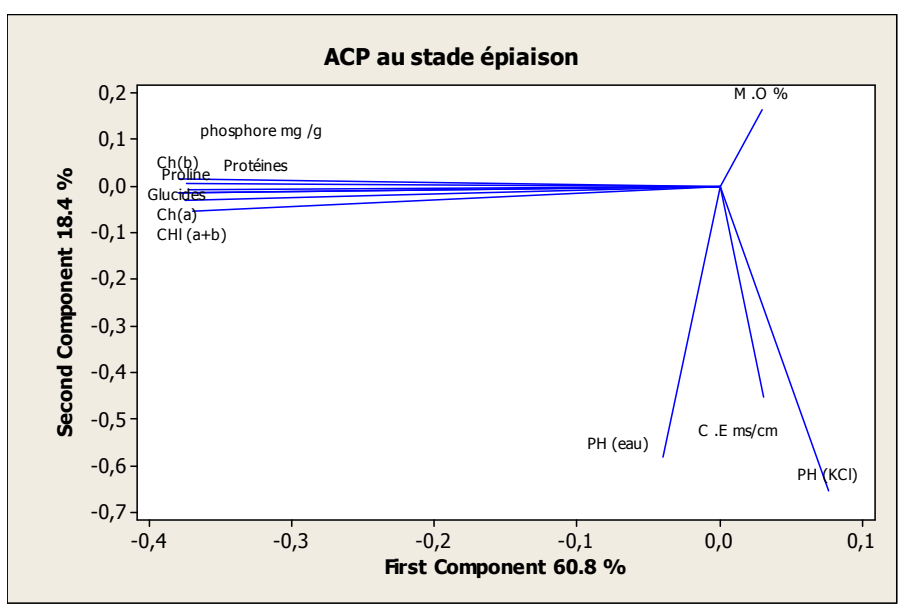

Figure 18. Principal Component analysis of the variables studied in the inflorescence emergence step

\section{Discussion}

The different studies have investigated the impact of $\mathrm{P}$ fertilization on the physicochemical characteristics of the soil. Such study was performed on a soil with granulometric characteristics dominated mainly by clay, which represented up to 44 to $55 \%$, and a ratio of sand that varied from 35 to $48 \%$ and a rate of silt varied from 5 to $9 \%$, so the experiments were carried out on clay soil to sandy clay soil. This clay soil is soft, hardworking, highly adherent and having an optimum retention of useful water (Deniz, 2004; Bonneau et Souchier, 1979; Morel et Fardeau, 1989). The study found that the $\mathrm{pH}$ of the latter are very important factor for the life of the plant. A remarkable seasonal variability was found, in which $\mathrm{pH}$ value ranged from 6.9 to 7.6.The $\mathrm{pH}$ near neutrality is well suited to the cultivation of wheat (Morel et Fardeau, 1989). At tillering stage, there was an increase in $\mathrm{pH}$ from 7.7 to 7.9 , which approximates the alkalinity. The high values ( 7.5 to 8.5 ) make difficulties for elements' assimilability by plants, which are indispensable for growth. At alkalinity, calcium phosphate solubility is limited, resulting in calcareous (Morel et Fardeau, 1989), but this variation may happens also in winter, where an increase in the relative volume of the liquid phase leading to a decrease in the electrolyte concentration, and thereby affecting the intensity of exchange processes, and at the end the $\mathrm{H}^{+}$ion content decreases which make increases the $\mathrm{pH}$. In summer, the opposite phenomenon occurs, leading to an elevation in the soil $\mathrm{pH}$ (Morel et Fardeau, 1989), the latter phenomenon was found in the actual study, where the soil acidification was linked to the release of $\mathrm{H}+$, inducing however an increase in the available phosphorus and consequently rises the uptake of $\mathrm{P}$ by plants, this is explained by the fact that acidification causes the dissolution of phosphate minerals (Hinsinger, 2001; Neumann et Romheld, 2002). Fertilizers also have an influence on soil pH (Morel et Pellerin, 2000), in this study the application of different doses of phosphorus have made a significant difference between the average $\mathrm{pH}$ during the pre-planting period.

For the electrical conductivity, the recorded values before sowing was from 0.1 to $0.14 \mathrm{~ms} / \mathrm{cm}$ and that after application of phosphate and nitrogen fertilizers. These values indicate that the soil is non-saline according to the scale of soil electrical soils conductivity (Diagnosis and improvement of saline and alkali, 2010). Then there was a slight decrease in the conductivity during the tillering stage $(0.06$ and $0.09 \mathrm{~ms} / \mathrm{cm})$, and that corresponds to the consumption of soil minerals, and secondly a decrease in the concentration of soil phosphate ions. This decrease continues until the end of the culture, where, after the harvest of the latter, there were electrical conductivity values of 0.05 to $0.07 \mathrm{~ms} / \mathrm{cm}$.

The content of organic matter in this soil experienced significant seasonal variation. During the tillering stage, there organic matter content of the soil raised up from $6.1 \%$ to 8.1 , this value may be due to the primary degradation of the previous crop, but during the heading stage there was a decline in soil organic matter content ( 0.9 and 1.2\%), this decrease is due to the phenomenon of mineralization (Morel et Fardeau, 1989; Messiga, 2010). Organic and microbial phosphorus is respectively 77 and $17 \%$ of total soil phosphorus; the mineralization of organic matter contributes to the renewal of soil available phosphorus, which can reach $1.7 \mathrm{ug} / \mathrm{g} / \mathrm{day}$. After harvesting the culture, there was a further increase in dry matter content of the soil, which is due to the phenomenon of restitution by crop residues (straw, root ...). After the application of different doses of phosphate fertilizers, the soil phosphorus content varied depending on the soil type, and also depending on the assay used. According to Olsen (Berset, 1997 in Frossard et Sinaj, 2004), the soil phosphorus content varies from 5.3 to 154 
mg $\mathrm{P} \mathrm{kg}^{-1}$; and by the $\mathrm{CO}_{2}-\mathrm{P}$ method, concentrations varied between 0.17 and $12.7 \mathrm{mg} \mathrm{P} \mathrm{kg}^{-1}$, while the P-AAEDTA method, phosphorus contents varies between 4.3 to $385 \mathrm{mg} \mathrm{P} \mathrm{kg}^{-1}$ (Frossard et Sinaj, 2004; Morel et Fardeau, 1989; Hinsinger, 2001; Johnston et al., 2001).

During the tillering stage, it has been noticed very highly significant differences in concentrations of soil available phosphorus, which ranges from 0.8 to $1.77 \mathrm{mg} \mathrm{P} \mathrm{kg}^{-1}$ soil. This variation is due to the phenomena of precipitation and adsorption of phosphorus in the soil (Barrow, 1987; Frossard et al., 2011; Hinsinger, 2001; Gervy, 1970; Messiga, 2010).

At heading stage, an increase in the content of soil available phosphorus was noticed, which is due to the phenomena of dissolution and desorption of adsorbed and precipitated soil phosphorus (Messiga, 2010; Hinsinger, 2001). At this stage, a drop in the rate of soil organic matter was observed, that its mineralization contributes to replacing the soil available phosphorus of $1.7 \mathrm{mg} / \mathrm{g} /$ day. Also, at this stage there was a weak negative correlation between soil available phosphorus and organic matter content. P ions can be transferred from the solid phase of the sol due to a concentration gradient (Jungk et Claassen, 1997), for example, the amounts of diffusible $P$ in 1 week vary between 1 and $39 \mathrm{mg} / \mathrm{g}$ in the $0-15 \mathrm{~cm}$ horizon.

Regarding the determination of pesticide residues in soil and according to ISO 10382 norms of 2002, which is applicable in all types of soil, the detection limits of pollution caused by pesticides is of the order of $0.1 \mathrm{mg} / \mathrm{kg}$ to $0.4 \mathrm{~g} / \mathrm{kg}$ (expressed as dry matter) culture. According to the present results, the quantities of pesticides vary from one stage to another, and also by many factors such as the application, the transport the depth, leaching, infiltration, and so on. These results are in line with those of (Kankou, 2004) who found traces of pesticide residues in soils near the river Mauritania; values vary between $8 \mu \mathrm{g} / \mathrm{Kg}$ and $38 \mu \mathrm{g} / \mathrm{Kg}$ dry matter culture. It can be said that there are link between the active materials and soil constituents, physical connections and the force of attraction, which may be due to the competition of organic matter and clay.

It can also distinguish the influence the semi-lives of the study pesticides, for the Cloquintocet-mexyl has a lifetime of about 943 days at $25^{\circ} \mathrm{C}$ at $\mathrm{pH}$ 5.Triasulfuron 31 has a lifetime of around 3 days at $\mathrm{pH} 5$, but at $\mathrm{pH}>9$ it remains up to 1000 days, while dicamba can stay 30 days at $\mathrm{pH} 5$ to 9 . It can be said that the Cloquintocet-mexyl is a persistent active matter that pollutes the soil (Schimazu et al., 2001; Taylor, 2012).

\section{Conclusion}

Particle size analyzes showed that the soil is characterized by a clay texture, the values of residual humidity does not exceed $8 \%$. The study showed a $\mathrm{pH}$ seasonal variability, it is in the vicinity of neutrality at the initiation of culture (7.22), to the vicinity of the acidity after harvesting (5.78); this variation of the water $\mathrm{pH}$ is due to the phenomenon of dilution.

For electric conductivity, were recorded values ranging from $0.13 \mathrm{~ms} / \mathrm{cm}$ at the beginning of the season, and then it decreases significantly to $0.06 \mathrm{~ms} / \mathrm{cm}$, which may due to the decrease in electrolyte concentrations. As a result, the soil solution is generally not saline.

In this study, the content of soil organic matter experienced significant seasonal variation, the highest value was observed during the tillering stage, while the lowest values were seen during the heading stage, which was due to the mineralization phenomenon.

After the application of different doses of phosphate fertilizers, soil available phosphorus varied very remarkably with the season, where the highest concentration was recorded at the beginning of the culture, while the lowest concentration was recorded during the tillering stage; this variation might be affected by adsorption and precipitation phenomena of soil cations.

The presence of two active residues (Clodinofop-propagyl and the Cloquintocet-mexyl) of Topik indicates that this pesticide is not fully degradable in the soil.

\section{References}

Albin, O. M. (1999). The university encyclopedia (p. 1399). Dictionary of Ecology Ed ISBN, France.

Anonymous. (2010). Diagnosis and improvement of saline and alkali soils. Hand book $n 60$ (p. 160). USA.

Baize, A. (2000). Factors influencing the adsorption, desorption and movement of pesticides in soil. Residue Reviews, 32, 29-92.

Barrow, N. J. (1987). Reactions with variable-charge soils. Martinus Nijhoff publishers, Dordrecht. http://dx.doi.org/10.1007/978-94-009-3667-6 
Berset, P. (1997). Variabilität der P-Verfügbarkeit in Böden des Kantons Fribourg. Diplomarbeit D-AGRL-ETHZ (p. 52).

Bonneau, M., \& Souchier, B. (1979). Pedology 2. Component and soil properties (p. 459). Masson, Paris.

Deniz, B. (2004). Guide of the analyzes Pedology (p. 256). Choice - Expression - Presentation interpretation. INRA, Paris.

Edwards, R., Brazier, M. M., Dixon, D., \& Cimmins, I. (2005). Chemical manipulation of antioxidant defences in plants. Advances in Botanical Research, 42, 1-32. http://dx.doi.org/10.1016/S0065-2296(05)42001-7

Feuillet, C., Langridge, P., \& Waugh, R. (2007). Cereal breeding takes a walk on the wild side. Trends In Genetics, 24, 24-32. http://dx.doi.org/10.1016/j.tig.2007.11.001

Frossard, E., David, L., Achat., Stefano, M., \& Bernasconi, A. (2011). The Use of Tracers to Investigate Phosphate Cycling in Soil - Plant Systems. Phosphorus in Action. Soil Biology, 26, 59-91. http://dx.doi.org/10.1007/978-3-642-15271-9_3

Frossard, E., julien, P., Neyroud, J-A., \& Sinaj, S. (2004). The phosphorus in soils. Current situation in Switzerland (Environmental Report No. 368, p. 180). Federal Office for the Environment, Forests and Landscape, Berne.

Gervy, R. (1970). Phosphates and agriculture. Problems of the farming business (p. 298). Dunod.

Hinsinger, P. (2001). Bioavailability of soil inorganic P in the Rhizosphere as affected by root-induced chemical changes: a review. Plant Soil, 237, 173-195. http://dx.doi.org/10.1023/A:1013351617532

Johnston, A. E., Ehlert, P. A. I., Kuecke, M., Amar, B., Jaggard, K. W., \& Morel, C. (2001). The effect of phosphate fertilizer management strategies on soil phosphorus status and crop yields in some European countries. World Phosphate Institute/Institut Mondial du Phosphate, Casablanca.

Jungk, A., \& Claassen, N. (1997). Ion diffusion in the soil-root system. Adv. Agro., 63, 53-110. http://dx.doi.org/10.1016/S0065-2113(08)60662-8

Kankou, M. O. S. (2004). Vulnerability of soil and water on the right bank of the Senegal River in Mauritania-laboratory study of the behavior of two pesticides ( $\mathrm{PhD}$ thesis, p. 159). University Mauritania.

Messiga, A., \& Jean, N. A. (2010). Transfers of phosphorus in soils cultures (Thesis, p. 217). Laval University. Quebec.

Morel, C., Planchette, C., \& Fardeau, J. C. (1989). Reasoned P fertilization of wheat. Agronomy, 12, 565-579. http://dx.doi.org/10.1051/agro:19920801

Morel, C., Tunney, H., Plenet, D., \& Pellerin, S. (2000). Transfer of phosphate ion between soil and solution.

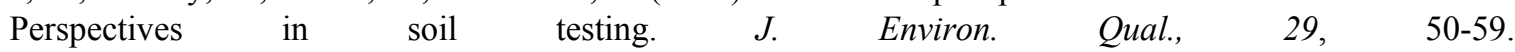
http://dx.doi.org/10.2134/jeq2000.00472425002900010007x

Neumann, G., \& Romheld, V. (2002). Root-Induced Changes in the aviability of Nutriments in the Rhizosphere. Plant root, the hidden half, third edition revised and explanded (p. 1120). New York, NY: Marcel Dekker Inc. http://dx.doi.org/10.1201/9780203909423.ch36

Rosinger, M., \& Kocher, R. (2007). Safener for herbicides. Modern Crop Protection Compounds. Wiley ISBN: 9783527314966.

Schimazu, A., Miyanaka, D., \& Schaufeli, W. (2001). Work engagement from a cultural perspective.

Taylor, V. L. (2012). The Activities of Herbicide Safeners in Wheat (Triticum aestivum L.) (Durham theses, p. 218). Durham University.

UK Agriculture. (2010). Farming and the countryside-What's going on and why. Retrieved September 1, 2010, from http://www.ukagriculture.com/statistics/farming_statistics.cfm

Zhang, Q., Xu, F., Lambert, K. N., \& Riechers, D. E. (2007). Safeners co-ordinately induce the expression of multiple proteins and MRP transcripts involved in herbicide detoxification in Triticum tauschii seedling tissues. Proteomics, 7, 1261-1278. http://dx.doi.org/10.1002/pmic.200600423 


\section{Copyrights}

Copyright for this article is retained by the author(s), with first publication rights granted to the journal.

This is an open-access article distributed under the terms and conditions of the Creative Commons Attribution license (http://creativecommons.org/licenses/by/3.0/). 